\section{THE STRUCTURE OF THE CORONA}

$A$ MONG the parties organised to observe the Total A Eclipse of 1869 , Aug. 7 , that sent from the Cincinnati Observatory was probably favoured above all others in the advantage of having a comparatively elevated station and an exquisite atmosphere. The publication of the work done by this party has been delayed by the fact that for a year subsequent to the eclipse I was wholly absorbed in the labour attending the maintenance of the "Weather Bulletin of the Cincinnati Observatory," and my subsequent occupations in the present office have entirely prevented me thus far from even attempting the reduction of our observations: the original note-books are at present packed away with the library of the Observatory, awaiting the removal and rebuilding of that institution.

My own attention was expressly given to the structure of the corona and coronal streamers, for which purpose I used the full aperture of an exquisite six-inch objective (one that had received a prize at the Paris Exposition Universelle), and which was loaned to the Eclipse Expedition by Mr. T. G. Taylor, of Philadelphia.

A short notice of the principal features noted by myself was sent at once to the editor of the Astronomische

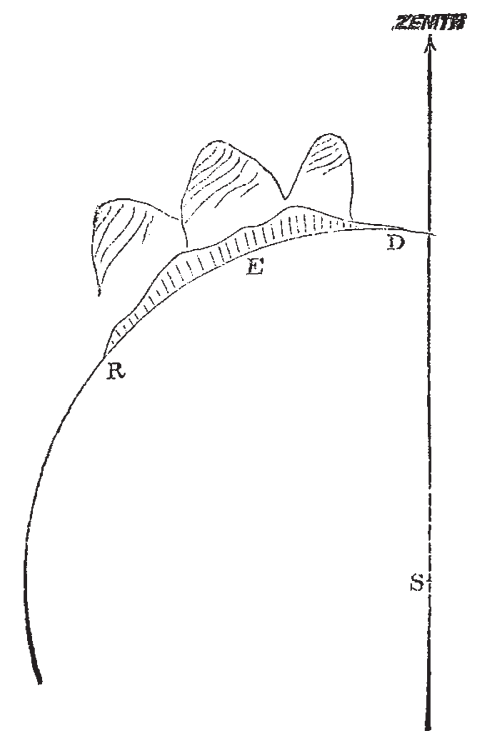

Nachrichten, but has not yet been published, and I therefore take the liberty of restating through your wide-spread journal the simple phenomena that I then saw.

Our station was at Sioux Falls City (formerly Fort Dakotah), in the south-eastern corner of Dakotah Territory, latitude $44^{\circ}$, longitude $97^{\circ}$, elevation about 1,500 feet above sea-level, in the midst of an extended plateau. Rain and cloud had continued up to a few hours previous to the critical moment, but the atmosphere during the eclipse was of surpassing steadiness and clearness.

The altitude of the sun at time of totality was about $40^{\circ}$, the local time 3.30 P.M., the duration of totality 4 minutes. No sooner had totality begun than, after sketching in most of the prominences as points of reference, I viewed the corona without darkening glasses, and with a magnifying power of probably 120 diameters. The whole interval of totality was, unfortunately, not at my disposal, owing partly to the very rough and faulty stand supporting the telescope (everything had to be transported 100 miles by mules into a wilderness), and partly to an interruption by one of the members of the party; but there seemed to me to be no doubt of the facts as recorded, nor was I conscious of the least undue emotion that might have interfered with my reliability as a witness, although it was the first total eclipse that I have had the pleasure of observing.

As seen through my inverting telescope, the structure of the large protuberance on the right hand lower limb was well made out. The neighbourhood of the sun was examined to a distance of its own diameter (a radius of possibly one degree from the sun's centre), but no trace of the coronal rays as they were seen by others of my party. The evidence as to the existence, shape, and positions of these streamers, as given by my six assistants, was conclusive as to their actual appearance, with the usual variations as to details.

That they were not detected by the six-inch glass was probably due to their diffused light and the small field of view. On the apparent upper and left hand limb of the sun, the six-inch glass showed the long series of red prominences depicted in the photographs published by the Naval Observatory. Above the greater portion of the arc of the sun's limb thus covered, and extending somewhat farther to the right, appeared to rise up three and possibly more conical masses of pearly light.

These were distinctly contrasted against the light diffused as the background of the field of view, and there was every evidence that they had an identical structure and cause. The outine of each of the pearly mountains was that of a rounded cone, as shown in the drawing-exactly resembling the kilns used in some branches of pottery and other manufactures. The apices of the cones were blunted or truncated, and not well defined ; the outlines of the sides of the cones were quite sharp down to within a few minutes of the sun's limb, when all three appeared to begin to lose their distinctive characteristics.

The height of the apices above the limb varied between one-half and two-thirds of the solar radius ; the diameters of the bases of the cones were probably included between seven and three minutes. Each apex was of a slightly dusky shade compared with the body of the cone.

The most interesting feature was an unmistakable striation upon the surface of each cone; the strixe apparently twisting spirally around up to the apex opposite to the movement of the hands of a watch, as represented in the accompanying drawing.

I noticed no colouration of these striæ other than their darker hue. The details of this striking and new phenomenon interested me so much that I naturally enough lost the observation of the third contact. The pearly cones were on that limb of the sun from which the moon was moving, and the details were every moment becoming more distinct, when the growing height of the bank of red protuberances was followed by the too speedy apparition of the glowing sun beneath.

Chagrin at the loss or imperfect observation of the third contact caused me to forget to note whether the three cones continued in view for any number of seconds thereafter. From the time of first recognising the pearly cones, until their disappearance, probably thirty seconds el'zed (I am writing without my note-book or other aici to memory), and I did not note any change in the appearance of the striæ.

The middle one of these cones caught my eye more especially, and the impression was that the other two, especially that on the right, was some distance behind it, or possibly obscured by a cloud of haze in the solar atmosphere. At the time it seemed to me that I saw in the central cone a column of smoke and hot gas ascending high above the area of red flames, then visible on the surface of the sun, and that the other two cones corresponded to other areas of red flames behind. The difference in character and position between these cones and the coronal streamers as observed by the others with the naked eye, and with opera glasses, seemed to argue that the latter were very probably individual subjective phenomena, or that they originated in the earth's atmosphere 
whilst the pearly cones existed in the solar atmosphere and constituted a true solar corona.

My long delay in making this communication to the scientific world will be excused, I trust, in view of the imperative demands made upon my time during the two years that have elapsed since the Eclipse of 1869 . I shall be deeply interested to learn whether the phenomena seen by myself may not be repeated on some other occasion and be studied by more experienced observers.

I may add that I had hastily provided myself with a Nicol's prism in hopes of making at least some trial of the nature of the coronal light; but the rude apparatus did not work satisfactorily, and I confined myself to details of structure; indeed, in my earnest gaze upon the novel phenomena I quite forgot the polarising apparatus.

Office of the Chief Signal Officer, U.S. Army, Cleveland ABBE Washington, Feb. 6, 1872

\section{EARTH-CURRENTS AND THE AURORA BO. REALIS OF FEBRUARY 4, 1872}

$\mathrm{T}$ is unfortunate that more accurate observations of the 1 electrical phenomena accompanying auroral displays cannot be made upon the telegraph wires of this country. The truth is, public business cannot be made to suffer for scientific investigation, and at such moments the disturbance of the wires makes it more than ever imperative that delays should not occur. The whole efforts of the staff are directed to maintain the communications intact, hence the observations made on February 4 are not very numerous, though they are sufficiently interesting to deserve record.

At Portsmouth twenty-six observations were made of the direction and strength of the earth-currents on a wire extending from Portsmouth to London, viâ the London and South-Western Railway-a length of 74 miles, giving a resistance of $995 \mathrm{ohms}$. These were as follows :-

\begin{tabular}{|c|c|c|c|c|c|c|c|}
\hline Time. & 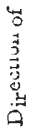 & 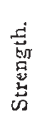 & Remarks. & Time. & 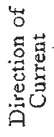 & 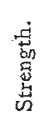 & Remarks. \\
\hline .54 & $P$ & $30^{\circ}$ & & 6.41 & $\mathrm{P}$ & $40^{\circ}$ & (No observa. \\
\hline 6. 8 & , & 20 & 苞蛋胥 & $\tau$ & - & - & tions made \\
\hline 6. II & ", & 10 & घ & 7.35 & - & o & between \\
\hline 6.13 & ", & $3^{\circ}$ & 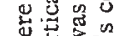 & 7.42 & $\mathrm{~N}$ & $4 \mathrm{I}$ & $(6.41 \& 7.35$. \\
\hline 6.15 & ," & 25 & 30 & $7 \cdot 56$ & $"$ & 68 & \\
\hline 6.17 & ", & 40 & 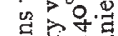 & 8.6 & - & o & \\
\hline 6. 19 & & 30 &. & 8.8 & $\overrightarrow{\pi T}$ & 0 & \\
\hline $6.2 \mathrm{I}$ & $\mathrm{N}$ & 15 & 跑. 月ี & 8.15 & $N$ & 35 & \\
\hline 6.23 & 3 & 24 & 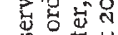 & 8.22 & $\mathrm{P}$ & 12 & \\
\hline 6.25 & $P$ & 20 & 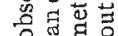 & 8.28 & - & 0 & No observa- \\
\hline 6.27 & 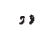 & 20 & مُ & $8.3^{\circ}$ & - & 0 & tions made \\
\hline 6.29 & $\rightarrow$ & O & 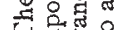 & - & 一 & - & between \\
\hline $6.3 \mathrm{I}$ & $\mathrm{P}$ & 8 & $H=8$ & 90 & $m$ & 0 & $8.30 \& 9.0$ \\
\hline 6.33 & ", & I3 & & $9.4^{\circ}$ & - & 0 & P.M. \\
\hline
\end{tabular}

$P$ means Positive from London to Portsmouth.

The officer who made these observations writes:"Strong deflections arising from earth currents were observed on all circuits except the local ones. The duration of the currents changed from north to south at intervals of a few minutes, and varied in strength from $\mathrm{I}^{\circ}$ to $68^{\circ}$. The strength of the current was proportionate to the length of the wire. Thus Chichester circuit (a short one) was affected less than the Guildford, and the latter less than the London circuits. The working was maintained to London with comparative ease by looping two circuits together at each end." The latter method is that usually adopted to overcome the disturbance due to earth currents, but of course it is only applicable in places where there are two wires or more.
Another officer at the Waterloo Station, London, observed the deflections gradually appear on every needle circuit, of which many concentrate at that station. They commenced about 2 P.M., and from that period to 8 P.M. they had all alike been more or less disturbed. It was noticed that the needles moved over gradually, not by a continuous motion, but by jerks, resembling that of the minute hand of a large clock. This has, however, been proved to be due to the friction of the pivots, and not to any pulsations in the currents.

The currents were always most apparent, and first no. ticeable on the longest lines, and as the lengths of the circuits terminating at Waterloo are very variable, this gradual appearance was very interesting. Lines running south-west and west appear to have been most affected.

All the wires in the Channel Islands were also very much disturbed. In fact Jersey was broken down to England for three hours, owing to the fact of there only being one cable. The section most affected was that between England and Guernsey. It was also noted that the wires in France were very much influenced.

The records from abroad show that, as in previous cases of storms of this character, the effect has been simultancous all over the globe. The French Atlantic cable was seriously affected; the strength of the current was at one time equal to 90 Daniell cells. It was at times im. possible to read even with condensers in circuit. The American lines were also disturbed in the East, West, and North, but not in the South.

It is much to be regretted that simultaneous observations cannot be made in various parts of the globe, detailing, in comprehensib!e units of measurement, the direction and strength of these currents, as well as the exact time of their appearance and disappearance. We might then arrive at some knowledge of their cause.

Southampton, Feb. 24

W. H. PREECE

\section{THE DARMSTADT POLYTECHNIC SCHOOL}

THE following epitome of the programme of the "Grand Ducal Hessian Polytechnic School of Darmstadt" may interest the readers of NATURE as a further illustration of the facilities offered in Germany for technical training of the highest and most practical kind.

The object of the school is stated to be a thorough scientific, as well as artistic, education, for all technical pursuits, assisted by appropriate practical exercises. The institution affords special facilities for the education of architects, engineers, mechanical and chemical technicists, manufacturers, craftsmen, and agriculturists. The institution is divided into the following sections:-(I) the Lower School; (2) the School of Architecture ; (3) of Engineering; (4) of Machinery; (5) of Technical Chemistry; and (6) of Agriculture.

The Lower School aims at giving a general instruction in mathematics, natural science, and design, as a foundation for the special pursuits taken up afterwards. For admission into the school it is necessary that the student shall be sixteen years of age, and have received such an education as would be afforded by the highest class of a "Realschule," or the third course of a "Gymnasium," with the exception of the dead languages. This implies a knowledge of algebra as far as equations of the second order, an acquaintance with logarithms, with plain geometry, and the elements of solid geometry, practice in German style, a knowledge of the outlines of history, and some practice in linear and free-hand drawing.

Examinations are held in the lower school at the end of each half-year, in the other divisions at the end of each year; a diploma is only given if the student gives satisfactory evidence of having completely mastered one of the branches of technical study in which special instruc- 